\title{
AANMERKINGEN
}

Over

Den OORSPRONG; GESTELTHEIT ; en AARD

der

\section{ZEE-WOR MEN.}

Die de Schepen en Paal-werken doorboren

door

Den Hr. R OUS SE T,

Lid van 't Koninklyk Genootfchap der Wetenfchappen van Berlia.

Met Kopere Plauten.

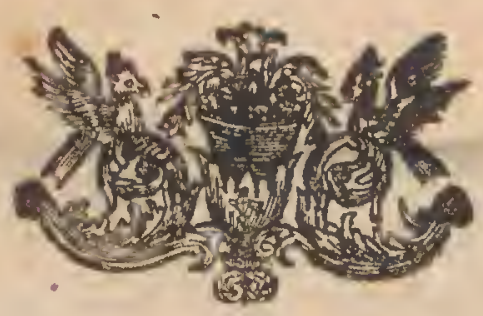

$$
\tau E L E Y D E N \text {, }
$$

By GYSBERT'LANGERAK, Bockverkoper in de Picters Choorfteeg. 1732. 


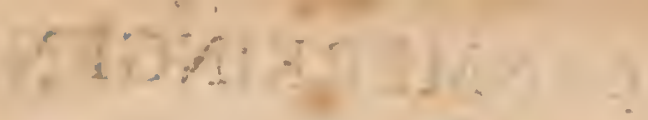

H:H HSOWT: 


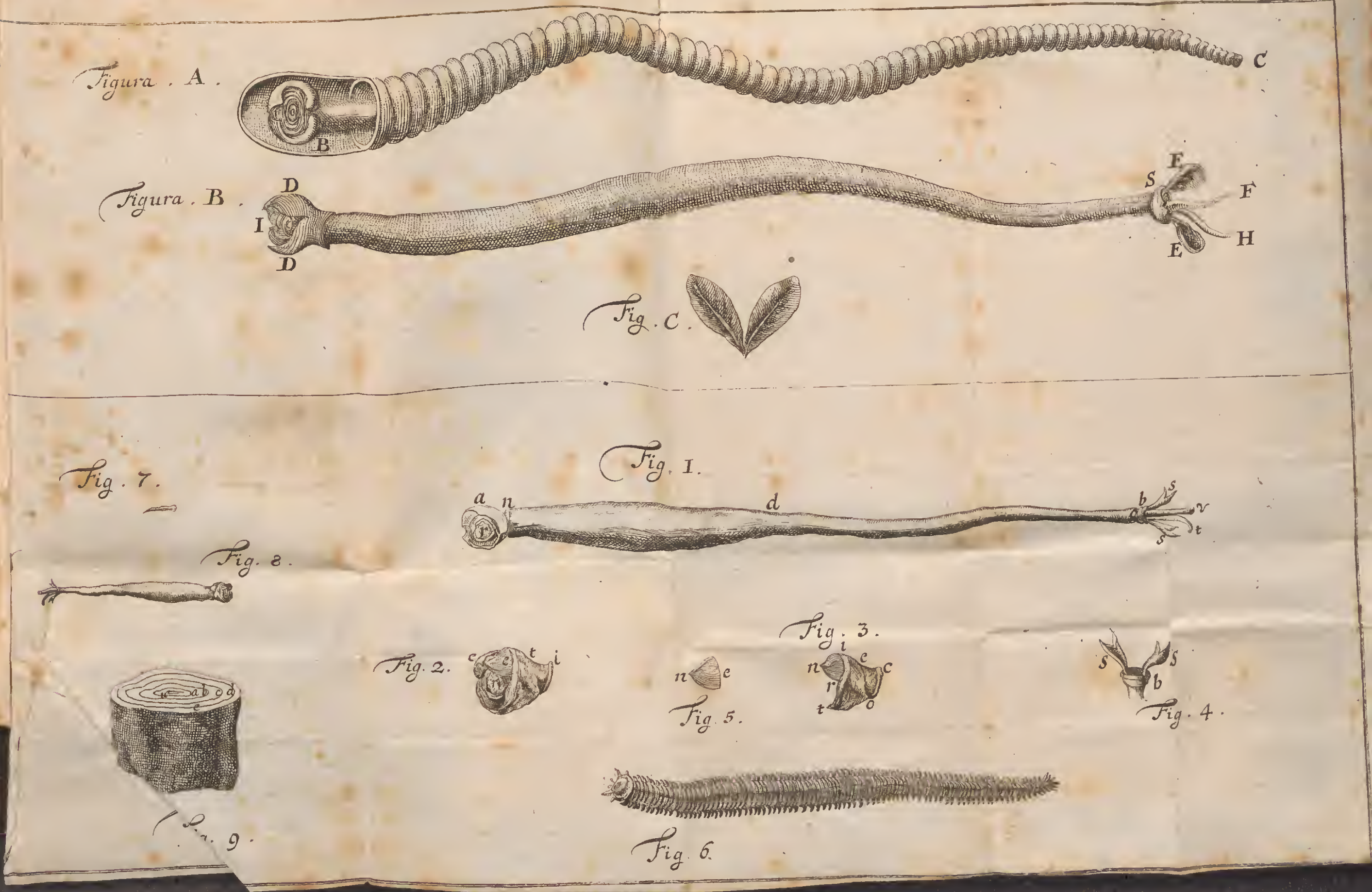


g. 10

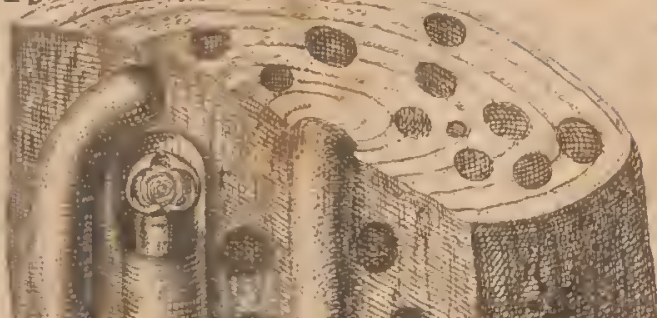

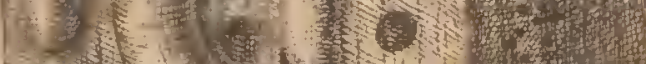

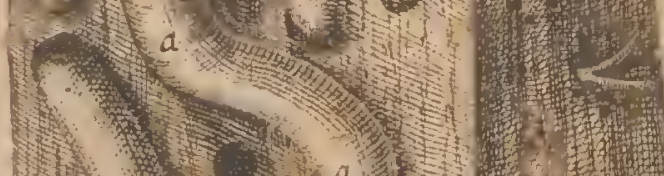

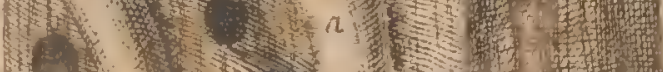

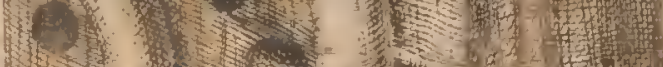

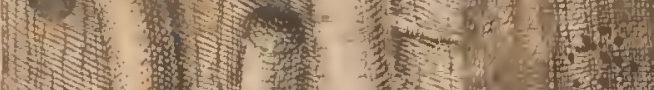
15. 6. d

2
3

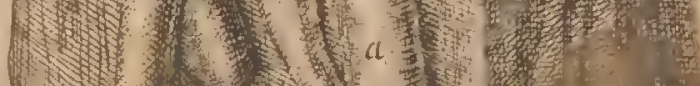

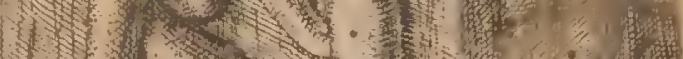

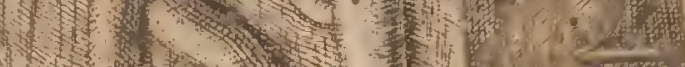

1
Nat

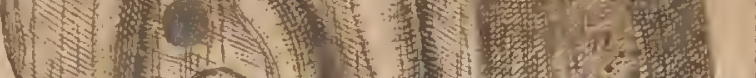

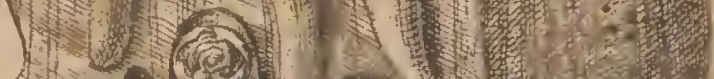

6 f.

$\zeta$

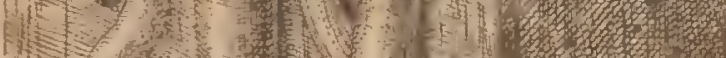

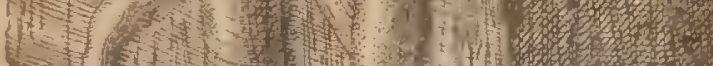

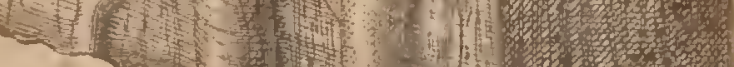




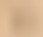

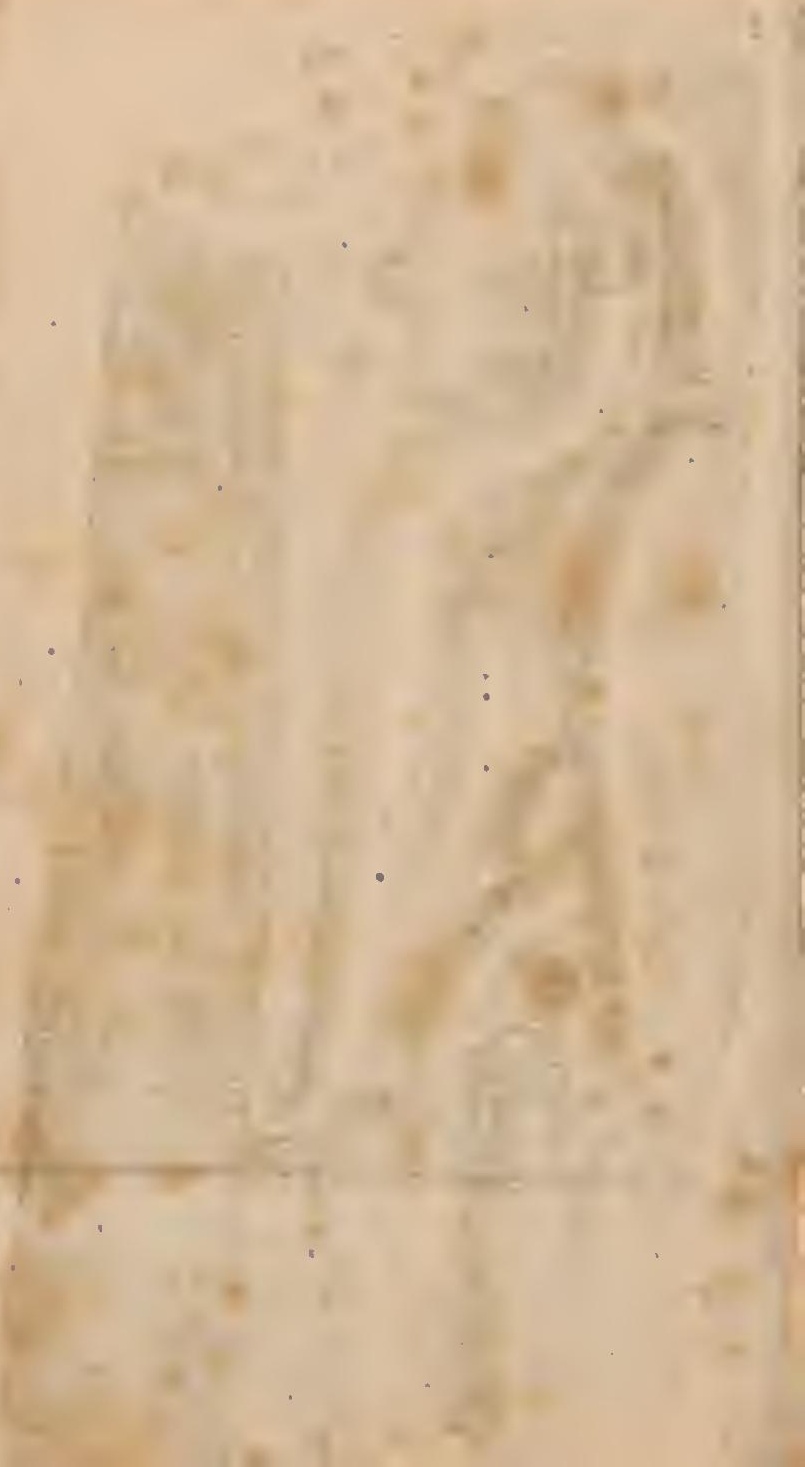




\section{A A N MERINGEN}

\section{O V E R D E}

\section{ZEE-W ORMEN.}

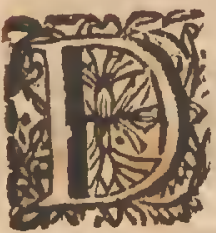

e fchade die zelrere vremde Zcewormen aan de Paalwerken der Dyken van Zeeland, Noordholland, Vriesland, en de Kuften van Vlaanderen toegebracht hebben, maakt zo veel geruchts, dat het niet te verwonderen is dit Verfcheinzel de weetgierigheit van 'tGemeen, en voor al die der' $\mathrm{Na}$ tuurkundigen heeft opgewekr.

Het belang, "r welk myn plicht van Onderdaan eifcht dat ik nemen moet in alles wat nadelig of nut kan zyn voor den Staat, waar in ik het geluk heb van te leven, heeft my aangedrongen om naar middelen te zocken tot voorkominge van dit quaat. Ik heb geoordeelt dat men, om hierin wel te flagen, alvorens den $V$ yand zou dienen te kennen dien men te beftryden heeft, en ten dien einde heb ik aan myne Lands-Ovęrheden de eerfte proeven * myner Waarne-

$$
\text { A } 3 \text { min- }
$$

* In cene MEMORIE (offfchriftelyk Opftel) over de Zee-wormen, peroorzaake, over hunnen aard, hunne voortgangen, en de middelen om hen uit te rocien; overgergeven aan de Hecren Staten yan Holland en Weftrricsland, in November. 
mingen over dat voornoemde Ongedicrte aan: fुcbricn. Zic hicr iets dat nog nitvoeriger is , er. 't welk zal lionnen dienen om de ZeeFormen wel tc doen kennen adn de genen die icrelve niet gezien hebben; en t'effens om de onware geruchten te wederleggen, dic door vyanden. van onze Rcpublik, of /door luiden dic wangunftig zyn orer 't geluk crl den rykdom harel gezegende Onderdanen, verfpreit worden.

Die geruchten zyn van alle kanten rerfpreit geworden, niet alleen in byzondere Brieven, maar cok in opentlyke Nietiws-papiercn. Zie hicr twee Staaltjes dantvan. De Courant van Bem zegt in-het $\$$ Artykel van den $H_{i a n g}$ van den 24 November $173^{2}$, met deze zelfde bewoordingen: Mcn arbeid met alle nanrfigbeit, om die Jyken van 't Land die 't micfo befchadigt zyin te berfiellen, en mecr dan fes duizend arbeidsluiden worden daar toe gebruikt; de liwoners der Dorpen die'" meefin met gevaar gedreigt worden, bebbein zich met bunne goedlenen clders begeven, om veilig te zyn. Men wind van tyd tot fyd onder de Dyken ongemene groote bolligheden, die daur door de Zee-wownen gemakt zyis. Het booft vain dat gedierte is zo basd, dat men cewen baner gebruiker most orn het te verplettcren; van dc: We Wormenzyn zo cene overgrote menigte, dat libt nict om wit te drukken is.

Geen éćn waar woord is'er in al dit verbaal. De Schryver toont dat hy zecr onkundig is in 't maakzel onzer Dyken, en dat lyy gecn't min-

6 No.XCVIH: van ded 6 Dicemb. $1 ; j 2$. tite. 
QVER DE ZEE-WORMEN.

Re denkbecld nog van dic Wormen, nog van derzelver gefteltheit hecf. 'Zie hier cen ander Verhaal dat nog vecl ongerymder is, fchoon het van cenen zeer vermarden Nicuwsfchryver van Dutsland kome, wiens Schriften aan byna alle de Hoven van 't Duitfche Ryk gevonden worden.

+ "De Stad Amfteldam ftant op het tipje van "haren ondergang, zynde alle' de Huizcnalkars, " dic op Palen gebout itaan, in zecr groot ge"vaar van in te ftorten, alzo de Wormen den "zclve doorknaagt, onnut genuaikt, en bititen , ftaat geftelt hebben van langer den laft telons nen dragen; zo dat men, om alie cle onder"gangen voor te lomer, waar mede die Huin "zen gedreigt worden, die reets beginnen tc "Waggelen en in ' $E$ water' te zinken, alle de kaf. ", telykiftc Mcubclen en Koopmanichappen daar s lit wegneemt, en elders brengt ter platze "daar die veilig zyn. Zelfs was het gevaar "al zo hoog geliomen, dat de rykfec Kíop. "luiden van vertrckken begonnen te fipreken, " om zich elders ter neder te zetten. Tive hor. "dert, zo grote als klcine Dorpen, belalyen , nog fes fraic Steden, wierden ernftelyk door "de Staten Generaal verzocht, zonder uittel "die plaatzen te willen ruimen, en zrch met is hunne gocderen naar vcilige platzen te bege"ved, met verlatinge hunne rHuizen en EiTen, "die in dezen winter, by den eerften water"vlocd,

† Uitrekzel van ecucn Brief van Duitsland, gedagrekent

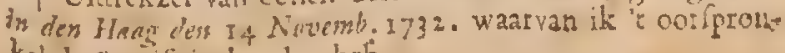
kelyk Schiff in handen heb. 


\section{A ANMERKINGEN}

"vloed, in groot gevaar zullen zyn van t’eene"Inaal onder water te raken; konnende de Do "Ken niet langer het gewicht en geweld van" "Zeewater wederftaan. Dit is myn Hecr, cer "nc kaftydinge enz. .......... It ga het $o^{-}$ verige voordachtelyk voorby, als cene aan merking zynde, die al zo buitenfporig als belagchelyk is.

Deze gantfche Brief is valfch; cn niettegenftande de Stormen van de Maanden October en November, en in 'rbegin van l)ccember, dic door eenen Noord-weften wind verwelktzy ${ }^{3}$ geworden, welke altyd gevaarlyk voor onze Kuften is; hebben nochtans onze Dyken, nog derzelver Paal-werken niet daar door geleden, cn gene de minfte opfchudding is 'er gewcelt. Geen ander Arbeitsvolk is 'er op de Dyken, dal" zulkc luiden die 'er het gantfche jaar door gcwect zyni ; en wat de Palen onder de huize' re Amfteldam betreft, zekcr, men zou van zyn verftand moeten berooft zyn, om allcenlyk zul$k c$ dwansheden te vertellen, nademaal de Paalwormen in geen zoet water konnen leven, ge lyk dat van Amfteldam is; dat zy nict dan in" hout leven, en niet in 't water nog in de anrde; en eindelyk, dat men, om te weten of de geheide palcu onder de huizen van de Wormen, doorlknaage zyn, alvorens wel; de Huizen dic 'er op ftaan diende afgebroken tc hebben, om dat te onderzoeken.

Deze Wormen zyn niet nieuw op onzc Kuften; want men heugt nog dat men van dic zcifde foort voor ontrent yyftig Jaren aldar' ge zien hecft. Doch allzo zy 'er niet verfchend 


\section{OVER DE ZEE-WORMEN.}

dan na de Hondsdagen, en ecn felle Winter dat ongediert doodde, voor dat zy nog zecr groot waren, vermenigvuldigden zy niet verder. $\mathrm{Zy}$ zyn ook bekend op de Kuften van Vrankryls en Italic; en ik heb Gelecrden gevonden dic daar ran gefproken hebben. De Hiftorie van dc Franliche Koninklyke Hogefchool der Weten- $z$ ic het Feran fchappen van 't Jaar 1720. hecf de Aanmerkin- $x>20$. te gen nangetekent, dic de Heer Deslandes, als AmftNatuurkundige, te Breft van die Wormen ge- dam in dann heeft, welke de Franflchen menen aldaar drukt, uit de Zce der Antilifche Eilanden gebracht te op de 34. zyn. "Hy nam cenige buiteplanken van cen Bladzy" "Schip, ter lengre van 10 of 12 Voeten, en de. "van 4 of 5 duimen dik. Hy zag dat de opper"vlakte daar van overal met kleine ronde gaat"jes van cen halve lyn * Diamcter's doorknatgt "was, en na dat die oppervlakie was weggeno„, men, zag hy verder vin binnen, dat alles daar "door de Wormen vertecre was, en vond 'erde "Wormen ook zclve. Zy zyn, zegt hy, on"trent eenen halven Voet, of iets minder, lang; "hun gantfche Ligchann beftant uit verfcheide"ne kringen; aan wecrkanten van den buik "hebben zy ontallyk veel klcine benen, die als "le met haakjes grewapent zyn ; en 'taanmer"kenswardigfte van alle is 't Hooft. Het word "geclekt yan twe evengelyke Schulpjes, die ann "weerkanten geplantft r.yn, aan 'c cinde fcherp "toclopen, en afzonderlyk en verfchcidelyk ic"der konnen werken. Deze foort van Helm, "wclkẻ het hoof van den Worm omringt, is "zeer hard in vergelykinge van 'toverige des lig"Chaans, 't wolk ongemeen racht en week is, 


\section{1) $\quad$ A $\triangle N$ N}

, in korten tyd in de lucht verdroogt, en cin", delyk tot ftof word. Het Hooft alleen maar "word door zyn bovengenoend befchutzel het. "langft bchouden.

Deze Worm gelykt niet naar de onze, dan alleen in de wapening dic aan ' $r$ Hooft is, en in zyne levensmanier, dic door den Autheur vervolgens befehreven word, en van ons op eene andere plants zal worden verhaalt. Wy hebben in opene palen eenen Worm gevonden, die cene ontallyke menigte van pootjes had, en waar van het lyf uit verfeheide kiringen of ringen beftond, zodanig als men hicr in Fig. 6. in de volle lengte en bicette afgebeclt ziet, maar het Hooft daar van is gantfch verfchillend by 't Houft dat door den Mr. Deslandes, hier. boven gemeld, befchteven word. En na dat wy een naukeurig onderzoek hadden gedaan, hebben wy bevolnden, dat de foort van Worm wan van wy hier fpreken, cigentlyk het Dennen-hout zockt, en 't beft daar in aard. Nog andere diergelyke hebben wy gevonden, die veel kleiner waren, maar evenwel van 't zelfdc maakzel, cu zulx in oude planken, die nog nooit in 't water waren geweeft.

De geleerde Heer Antonio Vallisnieri, Hooglceraar in de Genceskunde te Pidoua, geeft ons * de befchryvinge van cenen Worm, die wej- In de nig van de onze verfchilt, indien hy dezelfde eerfe niet is, en indien het verfchil niet van cene meling meer of min namkeuriger warneming voort-. vanAan- koint. Men kan de Figuur 13. alwaar de Worm merkin- van Vallisnieri vertoont word, vergelyken tegen getckent. 


\section{OVER DE ZEE-WORAEM. II}

Hy noeme ze 't Ongediert der Scbepen, en zegt, Ant. dat het (a) eene foort van Zec-wormen is, die zich in Vallisalle zodanige plantzen der Scbepen neficlen, welke nieri. altyd onder water zyn, en wel in planken die 't Venetie naaft by de oppervlakte des avaters komen. Dat zy 5710 . in zich.zolve in'thout fluiten, ecn ieder in zyne by- 220 . en zondere opening of buis, dic keyelswys of fpits toclo- volgende pende is, op de weyze der Scbelpuisjes, ann de bei-Bladzyde cinden open, en $\approx 0$ lang als de Wormen zeloe deas. $z y n$, welke van verfcbeidene grootte zyn, nazr dat derzelver ouderdom is; nuar dat de langfte wiet bowen cene balve Florentynfibe Lilkenmen balen, chs dat zy omtrent pinks dikte bebben. $\mathrm{B}_{2}$ Ain

(a) Une gaxzia di Tarli, a Vormi di Mare, die ansida is

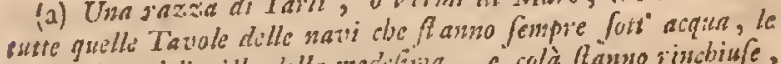

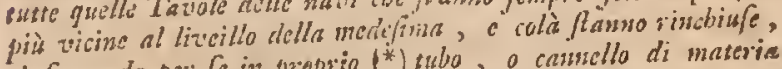

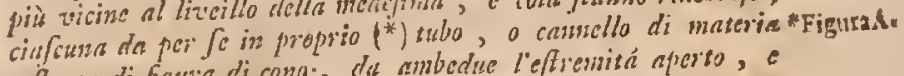

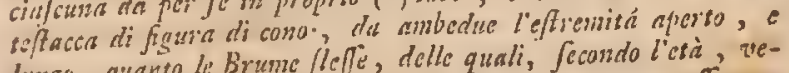

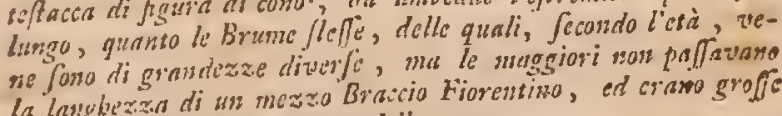

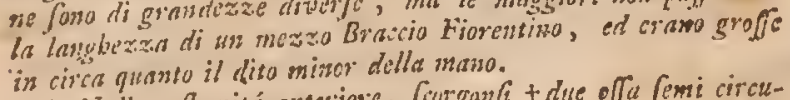

* Nella erftemisá anseriorc, fiurgonfi thue offa femi circu- = Biadz.

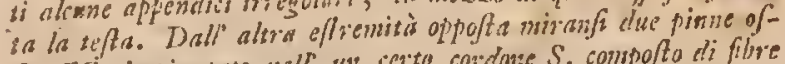
fee EE. impiantate well un certo cordone $S$. compoffo di fitre servofe, nel mezzo delle quali pinne fono fituate diue liunghe e recusade apprendisi carrofof $F$. H. insernamentite /canellate, cin-

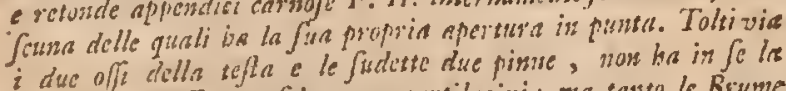

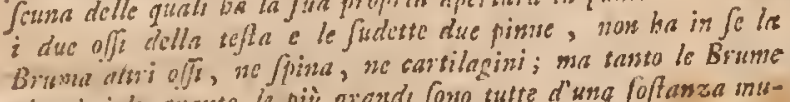

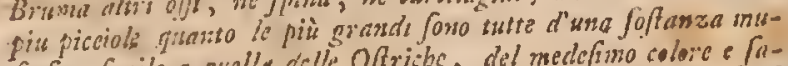

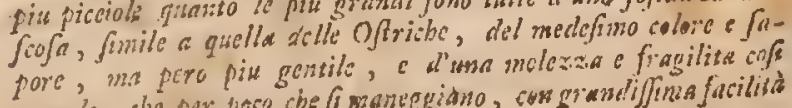

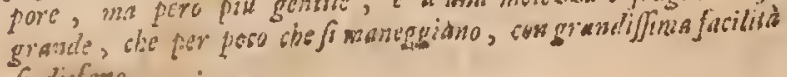
fi disfano. 
A.zn' 't uiteindc, alwanr't Hooft is, (dus vers volgt dic Heer) zyn twe Becndertjes, wan de gedaante cens balwen krings $D$. D. bol aan de exne, cn vorbeven aan de andere zude; zynde voortsecnigwints onregelmatig ann 't einde. In't midden dezer. Becnderitjes word het Hooft ontdekt. Lan't achtercinde zict nicn twe foorten van bcenacbtige $V$ innen $E$ E die and cone foort van riem, bindzel of freng S. valt zyn, wilk uit zenurwabtige $V_{c}$ alch befaat; cn tuffluen deze Vinnen zyn twe lange, rorde, en vlcesacbtigc Stantjes F. H. die van binwe bol zyn, cn war van bet uitcinde open is, Bebal. veis de two Beenderites van 't llouft, en de twe Vinnen, heeft dit Ongedicrte nog Beenderen, nom Grant, rog Kraakbecn; ch zo wel de grote als kle:w, zjn van cenc fofie of zelffandighcit, na by komunde by die van den Oefier, ook van de zelfis kleur en zrimak, madr zo ongcnecn week en teder, dat men ze nauwhliks kan anmraken, of ze, zyngebroken. Vervolgens doed hy eene befchryvinge van den Koker of Kas, dicin de Worm zich in de doorknaagoic opening makt, oin daar te huis. vaften.

Zic daar de Fefchryvinge van dien gelecteden Heer. I wat ons nu cens zien wat cen onder. fcheid'er is tuflchen die Wormen, dic in de Venetianfiche Zce warrgenomen zyn geworden, en de zulke, dice tegenwoordig op onze Kuften worden gevonden.

"ic lyer nu wat ik naukeiriglyk op de plaatzen zelve waargenomen hebbe, ann mcer dan dibend Wormen van verfcheide lengte en dik'tc, cn by 't openon van cenige fukleen hout, dic tecicinal daar van doorknaagt en doo:boort 


\section{OVER DE ZEE-WORMEN}

waren; als mede an andere Wormen, die ik als nog levendig vocde, om nog te naukeuriger warnemingen over den aard en wyze van doen van dat Ongedierte, te konnęn makcn.

Aan 't buitenfte van 't hout ziet men niet dan Fi.? 20 . cenige kleine gaatjes of openingen, waar van de wytte omtrent inie is : doar deze operingen komen de Wormen in ' $t$ hout, waar' uyt zy dat niet weder komen. Zy vallen zo wel ophet Eiken-Dennen-nls Elzc-hout , zyn zeer.gulzig en verflindende, en grocien in korten tyd in ligchanms grootte. Ik kan nog nict zcergen, of $\mathrm{xy}$ uit een Li, wit Verrotting, of anderzmes voortkomen; men zal dit cerft konnen zien na de Hondsdagen, 't welk de befte tyd tot zo cene waarneming is.

Volgens het Raport.der Gedeputeerden, die Vecbaal anngeftelt zyn geworden, om opzicht over het van de onderhoud der Dyken te hebben, blykt, dat die DykgraHeeren op den 12 Nuvember des Faars 173 6. zich Heemraop de plarizen legrasen bebbende, ecuen paal uit de den en zee badden doen belen, die gaxf on ongejichonden ge- Waarlcek, en "in den Yare 1718. ingebeit was geworden; va a cit dat zy desizelsen heboude doen fplyten, beron-Drechden badden, dat by van binnen t'ecwemail van de terland Wormen loorknangt was, war van eenige van Van do cene zeer ongersicene gruotte waren, nademual men'cr. I2. Jan. zag, dic de lengte van I4 Duinen Ainfeidlamfiche 5732. wnat badden, en worlker Bris of Nef, eveneens lofende als de draat van 't bout , ruisn geroeg was, om'er den ringer in to konthen firken.

De Opzieners van een ander quartier verha- Verbaal $\mathrm{lcn}$, dat $\approx y$ ecn fiuk van eenen groten paial, die nog van de

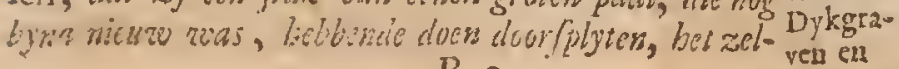


Heem- ve cveral met gatjes doorboort badden gevonden, raden vier die zo breed waren als tabakspipen.

Noorder In alle de warnemingen, die iklangs deKuft Cog- van Noordholland heb gedaan, heb ik gene hangens, van gere Wormen dan van 8 Duimen gevonden. den 29 Hun Ligcharm was cen have Meet-linic vań hun ry 1732 . Hooft at, en $\frac{1}{4}$ van ecu Duim dik: de Hooftwapening of Hclm was byna van $\frac{1}{3}$ duim dikre, en hunne gettalte is zodanig gelyk men by Fig. I. getckent zict.

HetHooft Hun Hooft is als eene foort van omgeheerFig. r. den Tcpel, op zyn lengft van een linic, en van eene zenuwachtige Stoffe, gelyk dic, welke den Mofiel aan zyne fichulp houd; en war van het gedeelte $r$, alwaar de mond des Worms is, de zelfule gectarnte hoeft als den mond van een menfis, 3ie grynt, met zyne lippen te rimpelen en in te krimpen. Dit gedeclte word omDeHelm, ringt, en niet bedekt, gelyk $V$ allisnieri zegt, Zie den van eenen Helm (n.a.) Fig. 1. cn befatat nic: Helm uit twe Becnderen, zo als dic zelfute Schryver byzon- getuigt, maar uit twe Schulpjes, welke afyeder. iig. I. zondert zynde, icter de gedante van de lielfe cener Slek hebben, Fig. 3, die in tweën gedeclt is. Dize Schulpen zyn volmaktelyk eveneens; de eene is ter rechter, en de andere ter linker zyde. Ieder kan in drie gedeoltens, Fig. 3. verFig.3. declt worden. o, $e, c$, makt den hals; $e, 0, i, i$, het Hooft van den Helm ; en cedriehoek $i, r, n$, het Voorhooft. Hals en Hoofe zyn uiterlyk gantfchelyk overecnkomende met de gedante der Schulpen, en hunne fehcidingen of trepen worden insgelyks in rig. 3. uirgedrukt. Dedive+ zic de-hok $t i, r$, $w$, is gantich renfchillend: dercl- 


\section{OVER dE ZEE-WORMEN.}

ve is witter dan 't overige, en word met kleine zondes ftrepen of fcheidingen bedekt, die van 't punt $n$, in Fig. 5 . allopen, en aan den voet $r, i$, eindigen; zo dat men, den vinger daar op houdende, gevoelt, dat die drichoek eenigzints rond, en als een rafp of vyl is. De twe vereenigde Schulpjes maken den gantichen Helm, Fig. 2. uit, welks gebruik wy hier na zullen verklaren. Men kan in de twe Figuren B. en 2. zien, dat deze Helm nog in iets van dien van $V$ allisnieri verfchilt. Gemelde twe Schulpen zyn aan 't Ligchaam van den Worm ter plaatze $(n)$ vaft, die 1 k den Hals noe-Fig. $x$. me; en zulx door middel van een zenuwachtig vel, van de zelfde foort als de zenuw die den Moffel aan zyne fchulp houd. Behalven dit zyn die twe Schulpen nog gezamentlyk vaft aan 't achterhooft van den Helm, door een vel vandie zelfde natuur; en hare gefteltheit is zodanig, ook zyn de twe punten (n) op zo eene wyze geplants, Fig.3. dat, wanneer de Worm zyn Hooft omdranit met zo cene beweging, gelyk de Slinger in een zak-horologiedoed, zy als dan twe verfcheidene linien befchryven, en kringswyze zagen, het een punt wat lager dan ' $t$ ander.

Alles wat tuffchen den Helm en 't ander ge-Het Ligdeelte van den Worm is, dat is, van $n$, tot $b$, chaam. is in twe vry ongelyke delen verdeelt, waar van het vooreinde $n, d$, 't welk men het Ligchaam kan noemen, om dat het de Ingewanden inhoud, van eene witte, vette, mergachtige Stoffe is, maar in lang zo vaft niet als die van den Oefter, hebbende omtrent het $\frac{2}{3}$ van den middellyn van den Helin. Het overige van 't Lyf $d, b$, 't welk mager, grysachtig van kleur, en usaar half zo 
De breed is als 't Voorlyf, kan den Staart genammt Staart. worden, die met cen bindzcl of riem b, eindigt, welke ten nuaften by van zo eene Stoffic als ' $t$ 't Hooft is, maar van zo cenc gedaante en milakzel niet, als Vallisnieri daar an geeft in $S$. Fig. $B$. Aan dezen riem begind een anhinangzel, bePootjes. ftaande in twe pootjes $(s, s$,$) die door Vallis-$ Fig. I. nieri Vinnen worden genaame, maar zeer verfchillende zyn by de gene die hy befchryft, Fig. C. of E. E. van de Fig. B. Want hy zegt al-

- daar: a) Hun Staart is aanmerkenswarardis, als gewapent zynde met twe Klingen of Zrvarden, die naar een blad gelyken 't welk uaar den binnenkant Fig. 1. wat bol is. Dezc $(s, s$, zyn op hun langft van anderhalye linic, zecr nauw omtrent het Bind$z c l$; 't welk zy valtychegt zyn, ein cene liniebreed van boven, alwaar men ze gefpleten ziet, in forme van een geite-pootje. Van buten zyn zy verheven rond, en een weinig hel van onderen; men zou zeggen, dat ze van yvoir waren, zo wit, glad en effen zyn zy; ze zyn harder dan den Helm, mat evenwel van cene fchulparchtige Szoffe.

DeStar- Tullchen deze twe Poorjes zyn twee Staartjes tijes. 1 . $(0, r$,$) cn (a, t$,$) war van de een recht en o-$ pen, en de ander wat gekromt an 't cinde is op de wyze van eenen hoorn: ieder van deze Staartjes is $\frac{1}{4}$ linie dik. De Worm lean dic plat maken, opzwellen, weghalen, verlengen, naur dat de gelegenheit vereifcht. Ik heb zomtyds

a) La lora coda è conffucrabili, effendo armara di due lamine di foura come fuglia aligamano concave verfo lo parte ino 
OVER DE ZEE-WOORMEN.

Éézien* dat hy het Staartje $(o, r)$ byna cenen zie $b, c_{j}$ Duim verlengt heeft, maar de verlenging van in Fig. dat van $(0, t$, is altyd minder.)

Ik heb verfcheide Wormen gëopent, zonder DeIngeeen Hart, of de andere gedeeltens daar in te vindien, die de $\mathrm{Hr}$. Valliswieri meent aldatar gezien te hebben, wanneer hy zegt: (b) Zy bebbeis een Hart under de Maag; var byna ronde gedaante en longreverig, gelyk twe pilaartjes, dis zich fobeinen wit te zetfen on in te krimpen, om een belder ers duor/cheinend bloed door de Slagaderen te drywe: welk bloeä in "tganifche Ligcbiam osizluopt, om daar zyne werkingen te doen, en weder manr't Haw keert. Il heb maar éen langwerpig Zakje gevonden, ter-lengte vart eenen Duim, iets mir of meerder, naw dat de Worm klein of groot is; cn onder dat zakje, tegeren's den rug aan, was nog cen ander Vaaje, 't welk mogelyk het Ey: erneft van het Dier kan geweett zyn. Dit zakje, 't welk waarfcheinlyls de Maag is, was vetvult met cene Stoffe; die men wel zien kon dat het. zangzel valn 't hout was; en naai grof Boekwcitemcel geleck. Tuficheu dit Zakje en dat ander Vaatje, is cen lange Darm, die van' 't Hooft tot Fig, 6 . an 0 tocloopt. ()ok loopt langs deri Staart cen vierkant Buisje, 't welk met dezelfde Stoffe ver-rig. $ז$ : vult is, die in de Maag gevonden word, maar van $d$, af van kleur verandert; alwaar zy roodC acli-

- (b) Hammó il loro Crơre, il quale è forto illentricello; dïBtids.

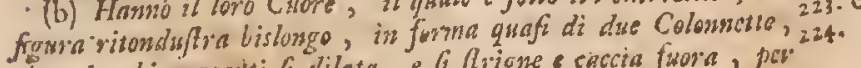
cie ad occbi weggetti fi dilata, efi flrigne e cuccia fuora, pev te fue arterie, uns fangue diafiano e traspartente. clue circola per

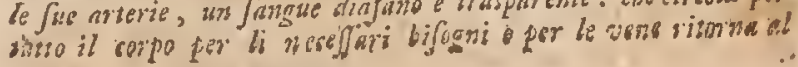
Curo. 
achtig uitzict, verbruinende of verdonkerende naar mate dat zy het bindzel $b$. nadert; ' $t$ welk ook ongetwyffelt aan den Stanrt eene andere klcur geeft dan die an' 't Ligchaam gezien word. Zie danr de Ontlced-kundige Befchryving der

Wormen. Laat ons nu eens zien wat zy in 't Hout uitrechten.

Oorfprong der Wormes.

Het zou alhier de plaats zyn, om hunnen oorpprong en gehoorte te verklaren. Wat het ecrle betroft, alles wat men daar van zou konnen $7 . \mathrm{cg}-$ gen, kan niet dan op giffingen gebout worden. Zommige menen, dat onze Schepen die Wormen uit Amerika gebracht hebben; maar men zou byna wel durven vaftftellen, dat deze mening genen grond altoos heeft, nademal die Wormen in die Zeën niet bekend zyn, max wel de andere foort, waar van de $\mathrm{Hr}$. Deslandes ven aast- Dusizendpoten genocmt worden. Waarfcheinlygehaaldo lier is het dat zy uit de Zcën die naar 't Noordelyk Aspunt der waereld leggen, overgebracht zyn geworden; want men vind zc voornamelyk op de Kuften van Ysland. Dit gevoelen zou onderfteunt konnen worden hier mede, namelyk, dat dit Ongediẹrt zyn Zant niet féhict dan in de Hondsdagen, dat is, op zodanigen tyd, Wanneer de Wateren in die Zeeftreelsen het meeft door de Zon verwarmt zyn geworden; daar in tegendeel, indiên zy uit cenig geweft tot ons quamen dat nader by ons is dan debrandende Luchtftreek, het zekerlyk onverfchillig vcor de Natuur zou zyn gewedit de Honsdagen meer dan eenigen anderen tyd te kiczen, alzo de warmte aldaur altyd byna even terk is. 
OVER DE ZEE-IVORMEN.

- Vermits wy onze Warrnemingen eerf in de Maant September lantitleden begomnen hebben, zo hebben wy de Voortteling van' de Wor-Hume men niet konnen zien, en weten gevolgelyk geb nict, of die uit Eyeren, dan enkelyk uit eene nymachtige Stoffe getchicd, dan of zy uir cenige verrotting voortkomen. Dit zullen wy den aanftaanden Zomer trachten te ontdekken, zo wel in Zee, als in onre Kamer, alwar wy dic Wormen zorgvuldiglyk voeden. 't Is waar, dat men onder de vrende Ligchamen, die aan 't 't Hout geheche zyn 't welk men uit de 'Zas haalt, gelykzaam cenige Schulpjes van ledige Eyeren bemerkt; doch dit bewylt nicts, want dit kan al zo wel van cenirg ander Ongedicre zyh, als van ' $t$ geen ' $t$ wclk wy thans onderzoeken. Vallisnieri, veel ftouter in dir.1tuk dan wy, alvorens vaftgeftel hebbende, (c) dat men deze Wormen onder zodanige foort van Gedierts moet flellen, 't welk woorticelt zonder zamenvocging ven bet Mannetje, en die Hermapbraditen genuamt worden, voegt daar by, dat bumne ronde, doorfcbeinende Eycren, die van eene Jlymacbitige foffo omringt zyn, zo lang op 't water dryeven tot dat zy eenig Hout aantreffen, alwaar zy zich dan vaft bechtcn, door ariddcl van dic flymacbtige jtoffe. Al-

$$
\text { C } 2 \text { daar, }
$$

(c) Di quegli che genceranno fensa il confortio del Mafohio, Mladiaza. - come gli clicamao Ermofroditi. . . . . ove ronde, diafaue, anch, efle sicomprgnatc e circoselate da un poco di nuccolse: gine vifcofetha, le quarli galligizno, e vengono poi gittate dale onsta diel mare apreffo le Truvele alle quali col losu vifco s'atznicano, e nafcomo, e le ssate picalijfrne Birume fi rivolgons poco, Hopo verfo la tavola, e prefo finto inconsminciano atra-

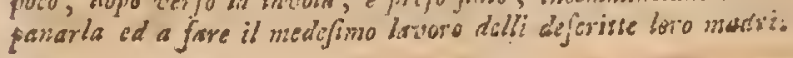


SA A A M ERK INGEK

darar,zegt hy, komen de Eyeren uit, en de jonge Wormen lechten zich dain op aanfionts aan't Hout', 't welk zy. doorboren, becinnende dus den zellden arbeid van bunn Moeders. Dit alles kin wel want zyn, en ik ben ook geneigt om het te geloven; derhalven, laat ons het als zodanig onderftellen, tot dat de ondervinding ons in 't recht heeft geftelt om van, gevoclen te mogen veranderen. Lo dra zy an? thout zyn gehecht, doen zy hun beft om daar. binnen te geraken; cn als dan moet hun Helm, op zyn meeft maar $\div$ Linie breed zyn. Zomtyds Zic Fig: zyn wel 2. 4. 6. 8., of 10 by mallander an 't 10. " ". hout vaft. Zy arbciden op de plats alwar zy. zyn, cn boren $2.4,6.3$ of 10 gaten dicht by malkinderen. Men heeft aan de palen van de'Zuiderzecbemerkt, dat de mecite gaten aan 't ondercin? ynina ar- dedicr palen zyn, omtrent cen voet van den grond; best. hoger worden 'er ook wel gevonden, man' ze zyn daar verder van malkander en in kleinex yetal. Ook hedt men palen gevonden, die aan de onder einderts zo doorknaagr waren als of een zeef was; zo dat zy, ahocwel het ovcrige ganf cin ongefchonden was, door. 't minft geweld dat: daar anu gedann wicrd, on verre vielen. "Ter plaatze alwaar de doorboringem gefclicut waren, geleck het van binnen wel naar luchtig gerezei? broad, of nar biffchuit, war in zo vele oogen of openingen gevonden worden als men hat doorfnyd, dat 'er flechts ecne zcer geringe afcheiding tunchen beide gezicn word,

$\mathrm{Na}$ dat de Worm in eenen paal is gekomen, dic in den grond geheit is geworden, boord hy regt door, tot dat hy ecnen ader, of licver cent? bedule vạ hout gevondẹ heẹt, dat hem'šbett. 


\section{Qver de ZeE-WORMEN.}

gelykt; en het zelve gevonden hebbende, draait hy rechtyniglyk mar boven toe, tot dat hy de touis of 't nelt vancenen anderen Worm aantreft, 'ţwelk hy niçt doorboort, wendende zich dan wat ter zyde af om een ander bedde te zocken. Dus is de $\mathrm{Hr}$. Deflandes in zyne mening bedro- Bladas gen geweeft, wannecr hy zegt: Dat, als twe $W$ or- $3^{6,}$ men malkanderen ontmoeten, de een dicn andren dood.

Zy zyn zcer gulzig, cn vordercn krachtig in hun boren, inzonderheit de jonge Wormen, die dat binnen zecr weinig tyds doell. Ik heb cenige van die jongen gevonden, dic 70 groot, gelyk Fig. 7. word angetoont, dicn voorledenen Zomer in 't Hout sckonecn zynde, op' 't latt yan Oetober nict meer dan twe duimen dane in gevordert waren, en zich toen rects zo groot vertoonden als in Fig. S. te zien iș. 'c ls hun Helm Fig. 2. of licve: de punten danr van ", Fig. 3. die zy gebruiken on het Hout te knagen, of cigentlyk om lict te doorboren of te vylen; met zo ecne beweging te maken, gelyk ik hier boven van den Slinger vin cen Zakhorologic gezegi heb; cn 't ' Zaagzel, of Afvylzel, 't welk in den mond of Tepel $r$ valt, dicnd tot Fig.ta vocdzcl voor den Worn. Naar mate dat zy in hun doorboren vorderen en groter worden, zet. hun Helm zich unt, on hun Nent desgelyks.

Zy laten tegen ann den binnenkant van de Buis of opening die zy doorbeort hebben, eene flymachtige tloffe, dic danar droogt, hard word, en eene foort van binnevoering, of liever cen binnenfte Buis mankt, in de gedaante eener lange Schclp, die zeer offen en witachtirg is, gelyk cne tabakspyp. Deze nymachtige ftofte is nict 
diklrex dan cen fpeclkaart, is van geen wederftand wanneer men die breken wil, en word evenwel in Wyngeeft niet ontbonden. De Worm onthoud zich in dusdanigen Koker, die zyn zeer teder Ligehaam befchermt, voor de oneffenheden van ' $t$ Hout dic het zouden lsonnen quetzen; zo dat hy glad daar dọor kan glyden, klimt en daalt, voor en achterwaarts gaat, zonder cenig ongemnk. Mogelyk dat dusdanige Koker hem mede befehermt voor de al te grote vochtigheit van 't Hout 't welk in 't water 1tat. Bladz. Vallisnieri geeft eene gantfch andere befchryvin221. ge van dezen Koker, dien hy zegt uit vericheidene kringen of ringen te beltaan. (d) Men ziet, zcgt hy, dat zy uit verfcheidene Beddens beftaan, gelyk de fchelpen wan Oefters en andere Scbelpvisjes, en daar by, dat zy de gedaante van kringen of rinFis. A. gen bebuen, die aan'troor-einde, dat is, an den grond von de Buis, beginnende, aldarr bet breelfts zojn, naur naar acbteren lopende, boe langer boe nawwer en tederder worden; en ter plantze alwuar. zy bet dikfte fibcinen, zyn zy aan de Buis vaftgebecbit,

(d) E fi vedie, cbe foro fatrifuoli, ofulde, come i giufoi delle Oftricbe $\dot{e}$ di altre onchig lie marine. ERernanente per. apparifcono compolai in foggin di tanti unelli, i quali principiando dal Tejtremitia anteriore, cioe dellin linfe del cono fi feargono motio:adi, ma avicinandofa werfo l'altra eftremita piu fottile, fo offervano molto Jpeffs: ed in quella parts appusiat, dove $i$ principali anelli cominciano ad aptarire cofi folti corri-

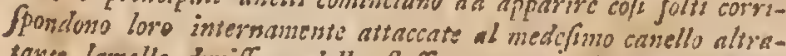
tante lamalle duriffeme della Aeffa materia teftacen, le quali fopre ponerdo, fo luss all altra guernifcono all iriorno tutta quclla eftremitia del Tubo, il quale, fe bene in :usto il refomse della fua conenvita rafembri aliquarito incgale con tutro cis the fun fuperficic ius:ura e lifcia, e non ifcabrofa corke leflersa. 
Over de ZeEWORMEN?

becbt, of pafjen op zo vele plaatjes van die zelfde fchelpachtige fioffe, die zeer bard zyn; welke dus de cene op de andere gevoegt wordende, de gantfche Buis befchermen. En alfchoon bet foheint dat de overige bolie daar van ongelyk is, nochtans is de binnenfte oppervilakte aldaar effen, eu geenzints ruw, gelyk de builen/te.

Als men dien Koker van 't Hout los makktzie Fig. en opent, vind men dien effen en gelyk, zo wel ro.4.a, $\cdots$. van buiten als van binnen, zonder eenige leden of ringen, gelyk men zelfs zien kan, wanneer men de gedecltens van die innerlyke Buis wel onderzockt. Dit heeft plaats in 't Eiken en EIzenhout; waar van de Aderen, of liever de verfchcide Bedden, ' niet zeer zichtbaarlyk afgezondert zyn; manr nu heeft de $\mathrm{Hr}_{\mathrm{r}}$. Vallisnieri zyne Waarnemingen aan cen Schecpsplank gedaan, en gevolgclyk is hy in ditgeval. Maar men moet bekennen, dat men cenig onderfeheid in ' $t$ Dennenhout vind, warr van de Beddens (gelylk hicr $a b, b c, c d$, ) door eene foort van een gefeheiden worden; welke koft van eene rood- $F$ ig. $s$ achtiger, harftachtiger), en harder ftoffe (gelyk de Linien $d, e$, of $b \%$.) is, dan die welke het Bedde uirmaakr. Zo lang als de Worm gene verhindering vind, boort hy door't Bedde dat regtlynig opwaarts loopt, en als danlis. zyn Neft volmanktelyk glad en efficn, zo wel van buiten als Fig. x०. van binnen; maar indien eenige verhindering, $a \cdot a, a$. gelyk de Buis van eenen anderen Worm, cen quant in 't Hout, een fpyker of diergelyk, hem noodzankt van cours te veranderen, laat hy na, verder opwaarts te boren, en gaat dan maar ter zyde in Horizontale Lnic regt uit, als wanneer 
24 A ANMERKINGE IN

hly verfcheidene van die roodachtige korften doors, knangt; tot dat hy an een ander Bedde komt, alwaar hy weder opwaarts boren kan. De moeire die hy vind om door dic korften te komen, uit rede dat zy harder dan 't ander Hout zyn, is oorzak, dat hy dezelvc zo fpoedigals hy kan ver:laat. Zyne Buis word nauver op dieplaits, en alzo de volgende kring, die zich in eene wekere thoffe bevind, breder is j-makkt dat de Ringen uit; die cchter zeer weinig zichtbaar zyn, en niet verder anhouden; alzo de Worm dan, gelyk gezegt is, als voren opwatarts gaat, en zyneBuis dan weder cffich word.

Fig. 20. Naar mate dat de Worm vordert, makkt hy zynen Kokcr, die zich uitftrekt van de kleine opening $b$ af, waar 'door hy gekomen is, tot aan de plaats $r$, alwaar de Helm arbeid om het Hout te dooizagen. Men moct annmerken, dat men in de zwaarfte palen, en die 't meeft doorboort zyn, gene opening vind waar uit een Worm zou gekoinen zyu, nog van voren nog. van achteren. Als zy eenmaal plants in 't hour hebben genomen, komen zy 'er niet weder uit; alzo de lucht. even dodelyk voor hen is als't water; want zo dra als zy van eene dezer twe Hoofftoffen doordrongen zy1r, moeten zy fterven.

Wy hebben 'r gebruik van den Helm en van 't Hoott verhandelt; laat ons nu ecns zien wat voor een gebruik het achter einde van den Worm hecft. Dat dier heeft byna altyd de Stantjes Fig. 10. $(0, r$,$) en (0, t$,$) in 't water. Hy laat die$ fo. 6 d. uitzalkken door de opening, waar door hy in 't hout gekonen is; en al washy 4 Vocten verre 


\section{Over de ZeE-Wormen.}

daar in gevordert, zo 'glyd hy rugwaurts nant dic opening, of liever naar dat tochrgat, ( want nergens anders kan hy idem halers, ) om zich rig. an van zyne Staartjes te bedienen. Vallisnic i is valn

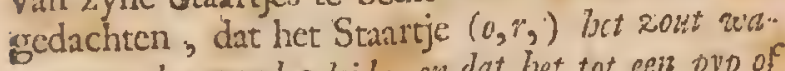
zer naar den mond geleil, en dat bet tot cen pyp of buis diend, waar door de Worm bet Ziewwatcr op: pompt, om bet zelve naar't looofit te brengen, enbet bout' $t$ wolk by doorzagen moet daar medte te bevoclstigen, on bet daar door te minder bard te moken, en zynen Helm te minder te flyten. Is "t nict war, ten minften 't is byzonder wel uitgevonden. .Wat my betreft, terwyl ik van deze Wormen cenige in een ftuk houts in myne kamer voede, heb ik bemerkt, dat onophoudelyk die twe ftaritjes uit de zelfde opening van 't hout kow men, al waar de Worm ingekomen was, endat die Dieren dezelve nu eens inhalen, en dan weder verlengen, meer of min. $b, c$, is altyd $p_{i g} . a_{v}$ segt en titgeftrekt, en verlengt zich krachtig; mnar $b, d$, zynde het kromachitig ftartje, blyft altyd in den zclfden ftand. $b, c$, beweegt en fchud zich zomwylen, mat op de minite betweging die in ' $t$ water of an ' $t$ hout gedaan word, zict men dat de beide ftaartijess van tyd tot tyd worden ingehnalt; doch op zo eene wyze, dat het viteinde $c$ dikwrils ter lengte eener linie buiten de opening blyft, en zich als een einde van eenen ledigen darm tegen' 't hout aanplakt: als de beweging ophoud, dan zwclt dat cinde van 't ftanric wederom, het beurt zich op, eli de ftartjes komen wederuit, als voren.

Door cene dezer twee Staartjes, (ik gcloof dat van $b_{2} d_{2}$ ) looft de Worm zyne uitwerpzes- 
$\approx 6$.

\section{A $\triangle$ N MERKINGEN}

Fig. 10. len, die bruinachtig, en als fyne $V_{\text {ermiceli zyto }}$ of Dcor' 't ander haalt by adcm, en trekt zo reel 0,5 . door middel van dit Staartje dat de Wormen hunne Copulatic of zamenyoeging verrichten. (Ik zal, na de annftande Hondstagen * een geZamen- wiffer vernlag hier van konnen doen.) Ondervocging tuffchen kan ik hier als eene watheit verzekederWol-ren, dat ilk in de Hondsdagen des Jaars 1732, mei: alm de zyde van eeri Fregatfchip, 't welk in de Haven van Metenblik lag, gezien heb, dat de Wormen het|Startic b, c, uit twe openingers die dieht by malkander waren, brachten, en zich daar te zamen voegden. De twe dus vercenigde Stantjes bedekten hunne uiteindens met cene foort van fchumachtig en roodachtig fpeekzel; en cenige minuten daama, wierden ze weder ingrchalt. Mar nu moet het zekerlyk toen de gewone teeltyd der natuur geweeft zyn, die de Wormen dis noodzaakte de Staartjes uit te fteken, om te trachten zich te zamen te vocgen; vant nooit komen anders die Staartjes buiten, wanneer het hout uit het water is, gelyk doenmanls het gemeld Fregat was, 't welk in dien tyd gekalcfatent wicrd.

Deze Warneming werpt omverie wat de $\mathrm{Hr}$. Vallisnieri vain 'c Hermaphrodismns van die Wormen zegt, dat is, dat zy 't manlyl en vroulyk geflacht beide aan zich hebben zouden; als mede het gevoelen van den Hr. Deslandes, welke

gift .

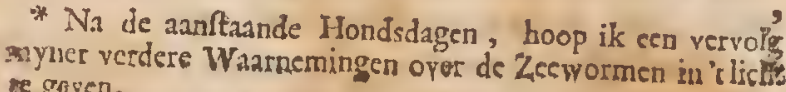
as goren. 
OVER DE ZEE-WORMEN. $=7$

grift, dat de Eyeren, wiar uit dat Ongedicric voortiomt, op de oppervlalite van 't hout gelege worden, door IVormen was cenezelfie fuort, 34 . mear die zich in de Zee ontbossden. Want, zegthy, bet blykt nict, dat de gene die ernmal in 't boat zyn, zicis tot de teling zuden konnen zartenvocgen, daar zy ieler uls in een byzonder Gevangenbuis van 't bout zyn opgefloten; als mede niet, dat zy uit die gerankeniffer zowlen komen, omz zich nair buiten op de oppesvlakte van't bewtwerk te begeven. "I Is waerfibeinlyk, dat de Zee-wormen, waar was ik fpreck, zo wol in 't water als in' bout konnen levers; mat dat zy in' huot alleen

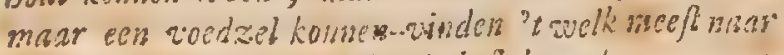
Euxnen zerack is, cuben't beft kan dwe's grocyen. Dat bet om die rede vok is dat de if ater-wormits bet bout zoeken, en aldare bunne lyeren legen, die vrucbibanr zy,z eerworden-door de zennenvoeging die in 't ruater geffebicd is; cin dat de Wormes die. uit deze Eyeresskumen, zo dra zy in 't bout raken, bet Voarrecb: verliczen van zich tot de icling to rerecrigen; zo dat bet goflacbt maar allech word voortgeplent dour de genen die zich in' 't willter onbouden, aiwar zy migelyk nict ke'sbaar zjo wor ecn zelfile foort of geflacbt, enz.

Dit mag met recht genocmet worden, wit ds

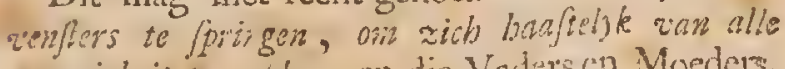
zasrigbeit te retder; en dic Vadersen Moeders, welke morelyk niet kenbaur zyz ran ecne zclfde foort of geflache te wezen, zyn bequam on voor allerlei antwoord den mond te fluien, zonder dac dit mogelye cens daal by behocit. Mans nu konnen wy op ' $t$ ivoord der Vifichers die langs deze Kanten zyn, verzekeren, dat zy nooir 
28 A A N M R K I G EN

yan zulke levendige Worbinen in 't water geronden hebben. Zy hebben wel cenige Wormen gevonden, dic nit palen waren gekomen welke aan ftukleen gchouwen waren, maar dic Wormen waren dond.

Gebruik Anibclangends het gebruik der Pootjcs of der Klaanwtjes, s, s, zo is 't waarichcinlyk, dat de Klanw- Natuur hun dezclve gegeven heuft, om zich tctiess,s, gens de binncwanden van hun Neft of Buis. tc. big. t. lionnen vafficihten, wanncer $z y$, na dit zy cui 4. zich natr de opcuing hebben laten afdalen of atflydon, 'tzy om himne wituerpzelen te lozen, (vant men vind dic in hun $N$ eft nict) 't $z y$ om al lone to bilen, (want \%y komnen 't nergens anders dxen) 'E $7 y$ on 't riater op te pampen, gelyk de / ir. ellisnien van geclachten is, (want liet water kan door het boveneinde hunuer Buis nict komen, dic gefloren is! of 'tzy eindelyt, bin zich tot de tcling zamen te vocyen, weder Mait" 't bevenfte rau de Buis mocten klimmen, an hun vocizel te zocken, met op nicuw hict hout te dronzigen. In dit opkimmon dicnes: hin de Klanwwejes, wanr van wy fpreken, en ciin acintor an den Stantzyn, welle ook nuet den Helm de conige valte en harde geciecltens \%) n dic men and dit Ongedicn vind. Al het ovepige, "welk door my het Ligcham genanme is rewarden, gelykt 7ece num de tofte van den ()efter, nict allecu ton opxichte van de kleur,

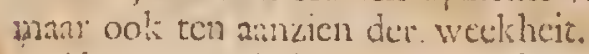

Alvorens te endigen, moct ili hicr nog anmerfen, dat incn in het doorklicren van de allergrootthe ituklien hout gene WWomelten rind dic door cis doarb voit, nog mut $c n$ in maikanier verwat 


\section{OVER DE ZEE-THORMEN.}

zyn; alle zyn zeafgezondert het cen van 't ander. door cene ruimte van hout, dic zomtyds nict dikker is dan een Speclkanrt: Ik heb hier boven gezegt, dat deze Wormon doorgaans rechtlyniglyk van onderen naar bovencn boren; 't welk men verftann moct van palen die in Z,ce gycliagen of gchcit zyn geworden. Vermits het. grootite gedecltc van 'tzaat of de Eyeren om-. trent cenen. Voet van den grond, en wat hoger, maar niet lager geplaarft word, hechten en reftigen zich de jonge Wormen insgelyks voor 't grootfte gedecle ann de palen op dic hoogte; zo dat men weinige gaten op de hoogte valn 3 of 4 vocten van den grond af vind. Van die voornocmde plaats boren de Wormen dan opwaarts in 't hout, tot omtrent ecnen Voet onder de gewone oppervlakte van ' $\mathrm{Z}$ Zcewater; en dat gedcelte van den panl is dan van binnen als doorzceft van de menigvuldige gaten; zo dat dewyl alle de Wormen den zelven byna opécne hoogetc aantiaften, zy geen genocgznam voed$7 c l$ voor hen vinden komnen, en dus een gedecle daar van therven moct; zulke allecn blyven beloniden, dic 't allerecrft begomen hebben in cenigen draat van 't hout regtlyniglyls. naar 'boven te boren. In 't hout 't wolk regt uit legt, gelyle de balken zyn dic aan den voct der dyken, dwars aver de palen heen, of tuffchen dezelve getlagen worden, om 't $t$ geweld der Zeegolven te bicken, boren de Wormen horizunclyk of regt uit, ma dat zy van onderen of tim bovcnen duat in gekomen zyn. Ik heb ccn ftuk van cen Lat van $2 \div$ duim dik, war in 32 Wormen waren, dic ook 32 omerent even grom 
te Buizen doorboort hadden welke zo regt waren, of zy door de konft zo gedraait of geboort waren geworden.

In de buitenplanken der Schepen, volgen de Wormen den draat van 't hout, en boren dus rege uit, van den voor-naar den achter-, of vain den achter naar den voorfteven; zo dat, nademazl zy nooit uit het hout komen, zy de plank niet aan alle kanten doorboren. 't Welk ook oorzalak is, dat de Schepen die vąn deze Wormen anngetnft worden, zo veel gevaar nict lopen, als zy wel doen zouden, indien dit Ongediert op ecne andere wyze boorde.

Befluit. Zic daar alle de Aanmerkingen, dic ik tot noch toe over deze Wormen heb konnen maken, en die dezelve nu hebbende doen kennen, den weg konnen banen tot de ontdekking van eenig middcl om dat Ifchadelyk ongediert uit te rocien, en dus onze Kuften, dat is onze Paalwerken ann dyken als anderzints te beviyden. En alzo nu door verfcheidene ondervindingen betoogt is, dat deze Wormen niet dan van Hout, en in Hout leven, uit het welk zy nooit komen, na cen-maal daar in gedrongen te zyn, als mede, dat zy in 't water komende, fterven, alwaar. ook gene van hunne foort gevonden word; 7.0 volgt. daar uit, dat nicts valficher kan zyn, dan alle die geruchten welke men verfpreit, van de gevaren waar voor het Land zou bloot gettele zyn; eveneens als of de Wormen de Dyken doorboordden ea ondermynden, en dat zy ook zelfs fieen en yzer konden doorkinugen.

Ik zal flechts nog eene Ainmerking hicr by voegen, namelyk, dat, vermits de Wormen 
Oper de Zee-wormen. 3 te waar van - hier gchandelt hcbben, niet voortkomen dan van 'tzant of uitfchiczzel der gencr dic in "thout zyn, dat zy dit zaat niet fchieten dan in de hondsdagen, en dat het zich als dan cerft ann de buiten zydens van 't Hout hegt; de fchepen geenzints gevaar lopen van daar van aangeftoken tc zullen worden, al lagen ze in een Haven, die vol van die Wormen was, mits dat het tuffchen den tyd van September en de volgende Miant July zy.

\section{E I N D E.}

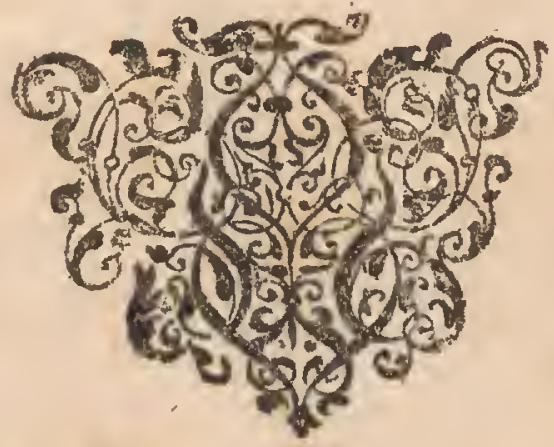




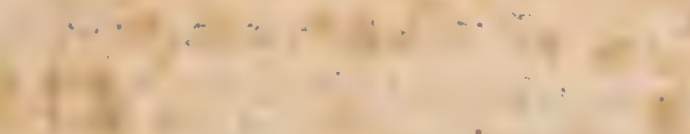

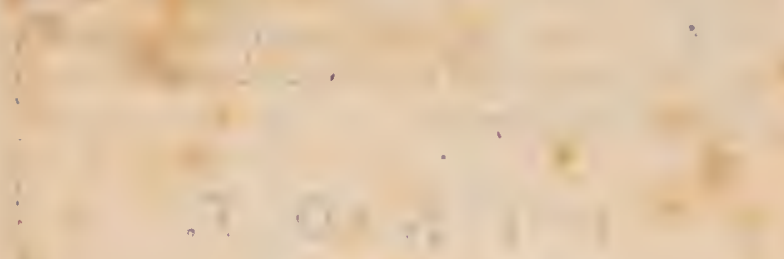



